San Antonio Review • San Antonio Review (Issue 2 | Winter 2019)

\title{
The Great Thing About Being Sometimes Hispanic
}

\author{
Alex Z. Salinas
}

Published on: Jan 17, 2019

Updated on: Aug 02, 2020

License: Creative Commons Attribution 4.0 International License (CC-BY 4.0). 


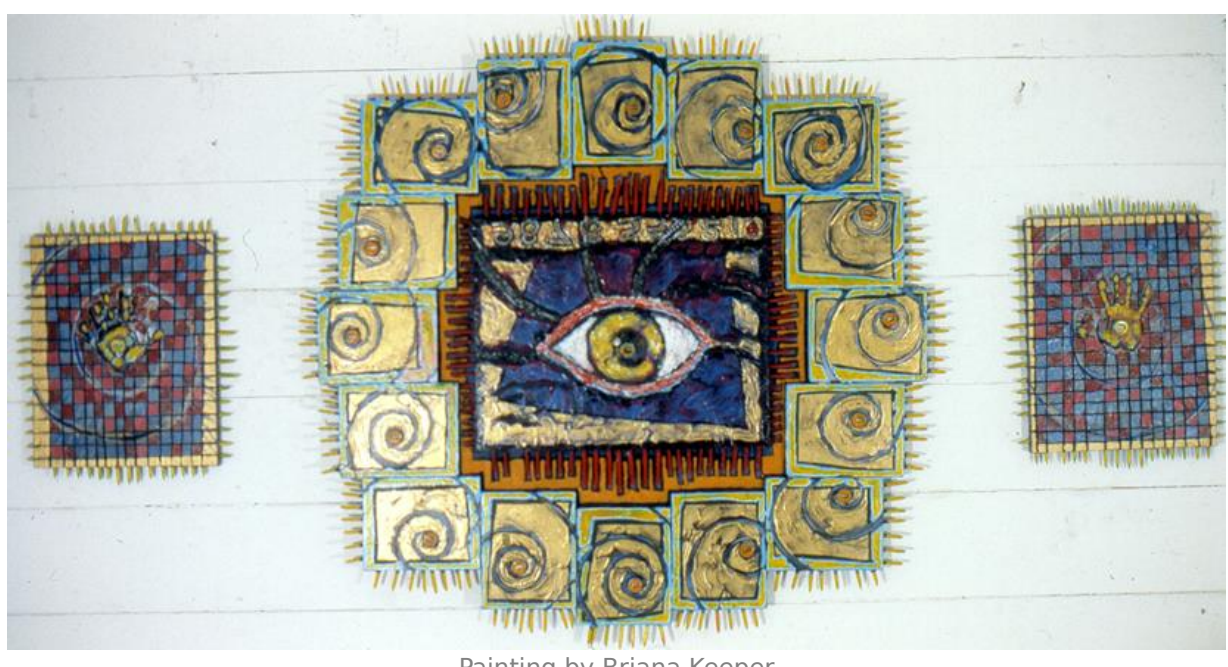

The part when I infiltrate the imperialist hive,

But not the part when my wings fall off

The part when I can afford to shop at Target,

But not the part when I still eat Taco Bell

The part when my skin looks white, But not the part when it tans after a hike

The part when I speak un poquito Spanish, But not the part when I can't understand Grandma

The part when I earn a college degree, But not the part when I can barely pay for it

The part when I have many brothers and sisters, But not the part when there're three mothers

The part when my father pronounces "chair" sher, But not the part when we laugh at him The part when I am mistaken for full white, But not the part when my name sounds full brown

The part when I am blessed with rhythm, But not the part when I hate to dance 
The part when I got it goin' on in my pants, can't keep it in

The part when I dreamt I was white, opened my eyes

The part when I dream I am Hispanic, open my eyes
But not the part when I

But not the part when I

But not the part when I

San Antonian Alex Z. Salinas earned a bachelor's degree in political science from St. Mary's University in 2011. His flash fiction has appeared online in Every Day Fiction, Nanoism, escarp, 101 Words, 101 Fiction, and ZeroFlash. He has also had poetry published in the San Antonio Express-News.

Brianna Keeper is a painter in Hunt, Texas. 